OPEN ACCESS

Edited by:

John L. Provis,

The University of Sheffield, France

Reviewed by:

Yunchao Tang,

Zhongkai University of Agriculture and

Engineering, China

Zhiming Li,

Central South University, China

*Correspondence:

Xidong Hui

xdhui@ustb.edu.cn

Specialty section: This article was submitted to

Structural Materials,

a section of the journal

Frontiers in Materials

Received: 30 July 2020 Accepted: 20 October 2020 Published: 13 November 2020

Citation:

Wu Y, Wang Q, Lin D, Chen X, Wang T, Wang WY, Wang $Y$ and Hui $X$ (2020)

Phase Stability and Deformation Behavior of TiZrHfNbO High-

Entropy Alloys.

Front. Mater. 7:589052.

doi: 10.3389/fmats.2020.589052

\section{Phase Stability and Deformation Behavior of TiZrHfNbO High-Entropy Alloys}

\author{
Yidong Wu ${ }^{1}$, Qinjia Wang ${ }^{1}$, Deye Lin $^{2}$, Xiaohua Chen ${ }^{1}$, Tan Wang ${ }^{3}$, William Yi Wang ${ }^{4}$, \\ Yandong Wang ${ }^{1}$ and Xidong Hui ${ }^{1 *}$
}

${ }^{1}$ State Key Laboratory for Advanced Metals and Materials, University of Science and Technology Beijing, Beijing, China, ${ }^{2} C A E P$ Software Center for High Performance Numerical Simulation, Institute of Applied Physics and Computational Mathematics, Beijing, China, ${ }^{3}$ School of Materials Science and Engineering, Zhengzhou University, Zhengzhou, China, ${ }^{4}$ State Key Laboratory of Solidification Processing, Northwestern Polytechnical University, Xían, China

Strengthened by Oxygen doping, the single-phase body-center-cubic (BCC) TiZrHfNbO refractory high-entropy alloys (HEAs) become strong and ductile. However, phase stability at intermediate temperature and the effects of Oxygen addition on the deformation behavior during tensile tests need to be well understood. In the present work, the phase decomposition of $(\mathrm{TiZrHfNb})_{100-x} \mathrm{O}_{x} \mathrm{HEAs}$ with Oxygen doping in the range of $x=0,0.5,1,1.5,2$ was examined at $873 \mathrm{~K}$. The formation of hexagonal-close-packed (HCP) solid-solution precipitates in submicron size, enriched with $\mathrm{Hf}, \mathrm{Zr}$ and $\mathrm{O}$ elements, were investigated by a combination of X-ray diffraction, transmission electron microscopy and atom probe tomography. Tensile tests of alloys annealed at both 1273 and $873 \mathrm{~K}$ were conducted. It was found that doping Oxygen increased the yield strength and maintained ductility for alloys annealed at $1273 \mathrm{~K}$, while formation of HCP precipitates after annealed at $873 \mathrm{~K}$ deteriorates the plasticity significantly. To unveil the deformation behaviors, in situ synchrotron X-ray diffraction experiments were applied in the current research. The singlecrystal elastic constants and shear elastic anisotropy of HEAs with and without Oxygen doping were calculated and found similar to those of "Gum Metal" Ti alloy. Yet current HEAs possess higher BCC phase stability than "Gum Metal", and no stress-induced phase transformation was detected during deformation.

Keywords: deformation behavior, ductility, elastic constants, high-entropy alloys, phase stability

\section{INTRODUCTION}

High-entropy alloys (HEAs), consisting of multi-principle elements with equi-atomic or near equiatomic ratio, have been attracting remarkable attention since the new concept of composition design was proposed (Yeh et al., 2004). Many HEAs have been found to have single solid solution phase in as-cast state or after annealing at high temperatures due to the contribution of high configurational entropy to the Gibbs energy. Of the HEAs developed to date, refractory HEAs are of special significance due to their outstanding mechanical properties at high temperatures and promising application potential in thermally-harsh environments, such as aerospace and petrochemical industries (Senkov et al., 2012; Senkov et al., 2013; Zhang et al., 2014; Pogrebnjak et al., 2015; Senkov and Semiatin, 2015; Miracle and Senkov, 2017; Vrtnik et al., 2017). However, the brittleness and poor malleability at ambient temperature are the key factors that hinder their industrial 
applications. To solve this issue, appropriate composition design and alloying, e.g., TiZrHfNb (Wu et al., 2014) and AlTiZrHfNb HEAs (Wu et al., 2018), could be promising approaches for realworld applications, considering these alloys exhibited great tensile ductility at ambient temperature.

For the applications of these alloys at high temperatures, maintaining the high phase stability in a wide temperature range during a long-term service is crucial. Recently, the phase stability of most studied HEA, CoCrFeMnNi, was challenged (Otto et al., 2016; Pickering et al., 2016). It has been found that after long-term annealing at $973 \mathrm{~K}$, two different precipitates enriched in $\mathrm{Cr}$ formed on the grain boundaries. Many works have been done on the phase stabilities of another exemplar refractory HEA, HfNbTaTiZr, at intermediate temperatures of 773-1273 K (Senkov et al., 2012; Senkov and Semiatin, 2015; Schuh et al., 2018; Senkov et al., 2018; Stepanov et al., 2018). Recent investigations by Chen et al. (2019) demonstrated that the HfNbTaTiZr refractory HEA decomposed into three phases, the body-centered-cubic (BCC) matrix, BCC precipitates enriched in $\mathrm{Ta}-\mathrm{Nb}$, and hexagonal-close-pack (HCP) precipitates enriched in $\mathrm{Zr}$-Hf when annealed at $973 \mathrm{~K}$ even after a short-term annealing of $2.5 \mathrm{~h}$.

In our previous works, we found that TiZrHfNb HEAs exhibit large plasticity and fine phase stability at intermediate temperature range, and could be promising refractory HEAs (Wu et al., 2014; Wu et al., 2018). However, the strength of quaternary TiZrHfNb HEAs is not outstanding. Interstitial solid solution strengthening was proved efficient in both traditional alloys and HEAs (Wei et al., 2011; Wu et al., 2015; Min et al., 2017). In this work, the effects of interstitial Oxygen element on the strengthening and toughening in O-doping TiZrHfNb HEAs is explored. Furthermore, the phase stability of these alloys at intermediate temperature and its effect on the tensile properties will also be investigated.

\section{MATERIALS AND METHODS}

Ingots of nominal composition TiZrHfNb undoped, or doped with varieties of oxygen contents $(0.5 \%, 1.0 \%, 1.5 \%$, and $2.0 \%$ in atomic fraction, also simply denoted by O-0, O- 0.5 , O- $1.0, \mathrm{O}-1.5$, and O2.0, respectively), were prepared from pure metals (purity higher than 99.99\%) and $\mathrm{ZrO}_{2}$ (99.9\%) via arc-melting in a Ti-gettered argon atmosphere. The ingots were flipped and re-melted at least six times for the purpose of ensuring compositional homogeneity. And during the melting process electromagnetic stirring was conducted. Alloys bars with a dimension of $10 \times 10 \times 50 \mathrm{~mm}^{3}$ was cast using a water-cooled copper mold. The as-cast bars were then cold-rolled into plates with thickness of $2 \mathrm{~mm}$. For following heat treatments, the cold-rolled plates were encapsulated in evacuated argon-backfilled quartz ampoules. Two different heat treatment procedures were conducted for the cold-rolled plates. One heat treatment was solid-solution treated at $1273 \mathrm{~K}$ for $0.5 \mathrm{~h}$ (depicted as SST for simplicity), and the other process was solidsolution treated at $1273 \mathrm{~K}$ for $0.5 \mathrm{~h}$, followed by aging at $873 \mathrm{~K}$ for $100 \mathrm{~h}$ (depicted as STA for simplicity). Both two procedures were ended by water quenching.
Phase identifications were conducted by X-ray diffraction (XRD) using $\mathrm{Cu} \mathrm{K}_{\alpha}$ radiation (D8 Advance, Bruker). The morphology and microstructure were characterized by a Zeiss Supra55 scanning electron microscopy (SEM), equipped with an energy dispersive spectrometer (EDS), and a FEI Tecnai $G^{2}$ F20 transmission electron microscopy (TEM). Samples for SEM were mechanically grounded to 2000-grit $\mathrm{SiC}$ paper and, subsequently electrochemical polished for the final surface clarification using a solution of $5 \%$ perchloric acid $+35 \%$ ethylene glycol monobutyl ether $+60 \%$ methanol (vol\%) with a direct voltage of $25 \mathrm{~V}$ at a temperature around $245 \mathrm{~K}$. The TEM samples were prepared by ion milling after mechanical grounded down to $\sim 40 \mu \mathrm{m}$ of thickness. Further in-depth microstructure investigations were made by three dimensional atom probe tomography (3D-APT) using the AMECA LEAP 4000X HR. A ZEISS AURIGA Dual Beam (FIB/SEM) workstation was used to perform site-specific lift-outs of specimen and annular milling to fabricate the needleshaped APT specimens following the procedures described in Ref. (Miller et al., 2005). The APT experiments were performed with a $50 \mathrm{pJ}$ laser energy, a repetition rate of $250 \mathrm{kHz}$, and a specimen temperature of $50 \mathrm{~K}$. The $3 \mathrm{D}$ volumes were reconstructed and analyzed using IVAS 3.6.12 software (CAMECA Instruments). Tensile tests were carried out on a CMT4105 universal electronic tensile testing machine with a nominal strain rate of $1 \times$ $10^{-3} \mathrm{~s}^{-1}$ at room temperature. The $\operatorname{dog}$ bone-shaped samples had a gauge length of $15 \mathrm{~mm}$, a width of $3 \mathrm{~mm}$ and a thickness of about $1.5 \mathrm{~mm}$. The samples were cut using electric discharging machining, along the rolling direction (RD).

The in situ synchrotron X-ray diffraction experiments were conducted on the 11-ID-C beamline at the Advanced Photon Source, Argonne National Laboratory, USA. The size of the X-ray beam was $0.5 \times 0.5 \mathrm{~mm}^{2}$ with an energy of $110 \mathrm{keV}$, and the loading frame controlled by displacement was applied in situ to the tensile samples during the tensile experiments. The diffraction patterns were collected by a two-dimensional (2D) GE detector of $2048 \times 2048$ pixels with a spatial resolution of $200 \mathrm{~mm}$ (pixel size). The loading direction ( $\mathrm{LD}, \varphi=90^{\circ}$ ) is parallel to the rolling direction (RD). The obtained 2D diffraction images were processed by Fit2D software. One-dimensional (1D) diffraction profiles were obtained by integrating along the specific azimuth angles over a range of $\pm 5^{\circ}$ in the $2 \mathrm{D}$ diffraction patterns. The calculated lattice strain indicated the change in the interplanar spacing (d-spacing) with respect to the initial state, i.e., $\varepsilon_{h k l}=$ $\left(d_{h k l^{-}} d_{0}\right) / d_{0}$, where $d_{0}$ and $d_{h k l}$ correspond to the interplanar spacings for different (hkl) crystalline planes without and with an external stress, respectively.

\section{RESULTS AND DISCUSSION}

\section{Phase Stability}

Figure 1 shows the XRD patterns of SST and STA alloy. Apparently, only one phase with BCC structure was formed in all the SST alloys. Addition of 2.0\% Oxygen increased the lattice constant of O-0 from $\sim 0.3529$ to $\sim 0.3542 \mathrm{~nm}$. However, a secondary phase with HCP structure emerged in all the O-doped alloys after STA process. And the intensities of the 

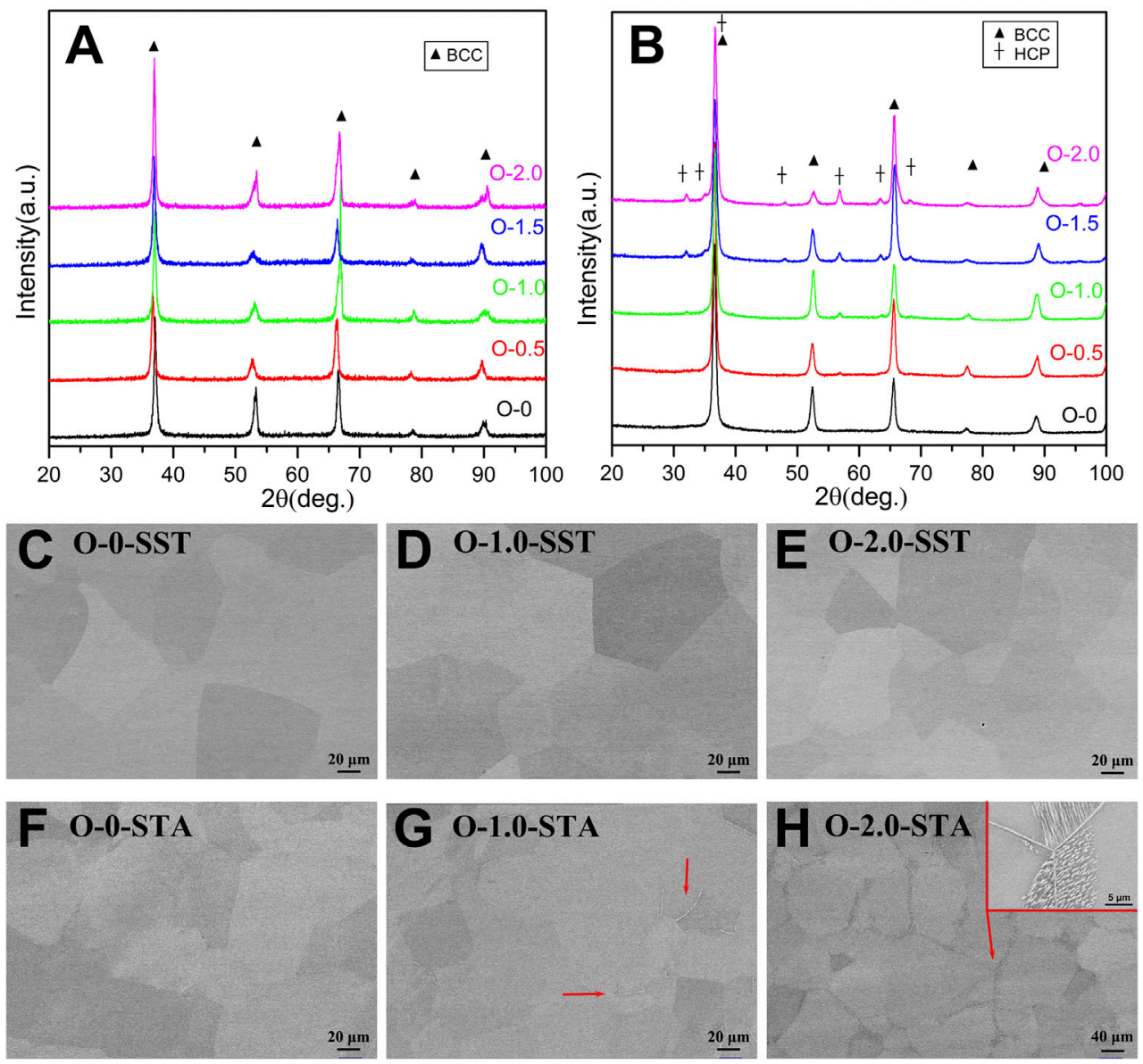

FIGURE 1 | X-ray diffraction patterns for TiZrHfNbO HEAs with different O concentrations in (A) SST and (B) STA states; Representative back scattering SEM images for SST and STA specimens with different O contents, (C) O-0-SST, (D) O-1.0-SST, (E) O-2.0-SST, (F) O-0-STA, (G) O-1.0-STA and (H) O-2.0-STA.

HCP peaks increased with increment of $\mathrm{O}$ concentration, indicating increase of the volumes of HCP phase. The lattice parameters of the HCP phase are $a \sim 0.3195 \mathrm{~nm}$ and $c \sim$ $0.5072 \mathrm{~nm}$, while the BCC matrix of STA O-2.0 have a lattice parameter of $\sim 0.3426 \mathrm{~nm}$, which is apparently smaller than that of SST O-2.0. The decrease of matrix phase lattice constant implies the segregation of elements with large atomic radii (Hf and $\mathrm{Zr}$ in this work) into the precipitate phase, and this will be confirmed in the following sections.

The microstructures of O-0, O-1.0 and O-2.0 HEAs underwent SST and STA processes were shown in lower part of Figure 1. After heat treated at $1273 \mathrm{~K}$, all the SST samples show a typical recrystallization microstructure with equiaxed grains, and no secondary phases formed. As for the STA samples, O-0 still formed single phase microstructure. However, a secondary phase, which appeared in bright contrast, emerged at part of grain boundaries in O-1.0. As for O-2.0, almost all the grain boundaries were covered with this secondary phase, and needle-shaped and dot-shaped precipitates started to develop in the grain interiors.

Figure 2 shows the bright-field (BF) TEM images of SST and STA O-2.0 samples. No precipitate was observed in the SST sample, and the corresponding selected area electron diffraction
(SAED) pattern confirmed the BCC structure of the matrix. Needle-shaped precipitates along grain boundary were observed in the STA O-2.0 sample. The SAED patterns obtained from the area marked by red circle in Figure 2B confirmed the BCC matrix and the HCP precipitates. The crystallographic orientation relationship between this HCP phase and the BCC matrix is revealed as $\left\{\begin{array}{lll}1 & \overline{1} & 1\end{array}\right\}_{\mathrm{HCP}} / /\left\{\begin{array}{lll}1 & \overline{1} & 0\end{array}\right\}_{\mathrm{BCC}}$ and $\left[\begin{array}{lll}0 & 1 & 1\end{array}\right]_{\mathrm{HCP}} / /\left[\begin{array}{lll}1 & 1 & 1\end{array}\right]_{\mathrm{BCC}}$, which is different from the case of annealed HfNbTaTiZr (Chen et al., 2019).

To understand the formation mechanism of HCP phase, the elemental distributions, especially for $\mathrm{O}$ element, of the constituent phases in O-2.0 samples are analyzed by $3 \mathrm{D}$-APT method. The atom maps of SST O-2.0 displayed in Figure 3A show good homogeneity in elemental distribution. However, the atom maps of STA O-2.0 show clear boundary within the tip sample. The elemental-concentration profiles generated from the cylinder area across the phase boundary in Figure 3B is shown in Figure 3C. The composition of the precipitate was determined to be $\mathrm{Hf}_{38.3} \mathrm{Zr}_{44.2} \mathrm{Ti}_{9.3} \mathrm{Nb}_{0.4} \mathrm{O}_{7.8}$, while that of the matrix was $\mathrm{Hf}_{19.3} \mathrm{Zr}_{17.2} \mathrm{Ti}_{29.4} \mathrm{Nb}_{33.0} \mathrm{O}_{1.2}$. Apparently, the precipitate is enriched in $\mathrm{Hf}, \mathrm{Zr}$ and $\mathrm{O}$ comparing with the nominal composition. As characterized by Lei et al. (2018), the addition 

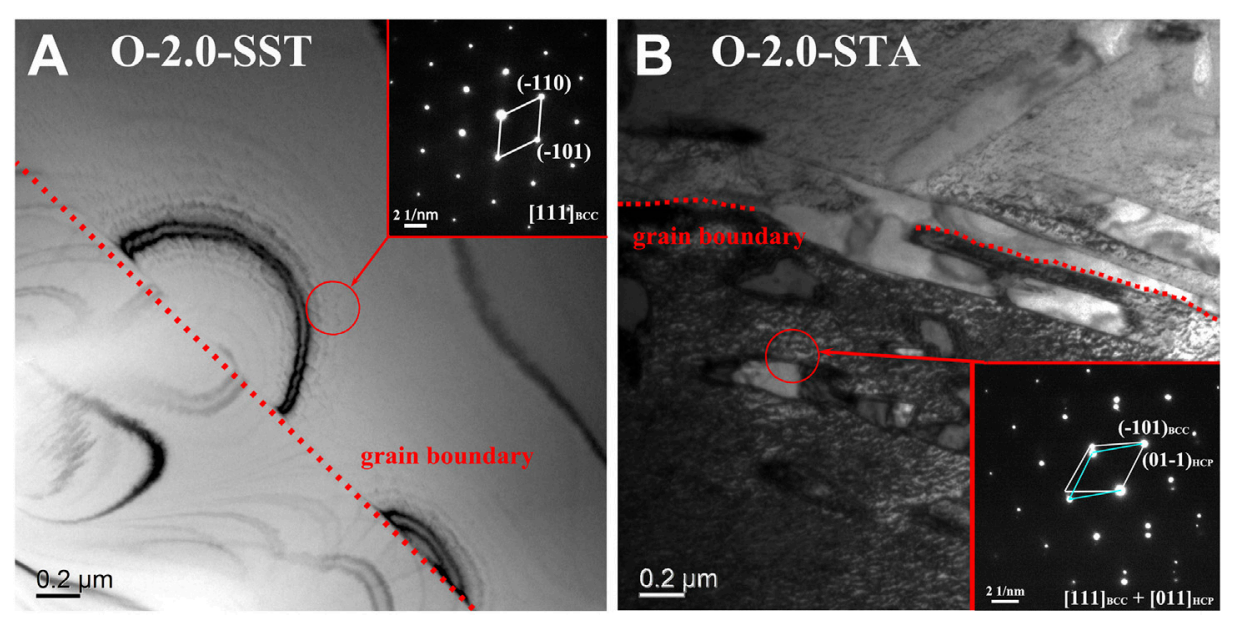

FIGURE 2 | Bright-field TEM images of (A) O-2.0-SST and (B) O-2.0-STA. The insets are selected area electron diffraction (SAED) patterns corresponding to the areas marked by red circles.

of $\mathrm{O}$ results in the formation of so called "ordered oxygen complexes, OOCs", which is ( $\mathrm{Ti}, \mathrm{Zr}$ )-rich, contain more than three at. \% $\mathrm{O}$ with a volume of several nanometers and contribute to the good ductility in the as-cast O-2.0. It is rational to assume that the precipitates formed in current STA O-2.0 origins from these OOCs. Both the mixing enthalpies for $\mathrm{Nb}-\mathrm{Zr}$ and $\mathrm{Nb}-\mathrm{Hf}$ atomic pairs are $4 \mathrm{~kJ} / \mathrm{mol}$, while that for $\mathrm{Nb}-\mathrm{Ti}$ pair is $2 \mathrm{~kJ} / \mathrm{mol}$ (Takeuchi et al., 2005). From a thermodynamic point of view, at temperatures much lower than melting point, without the full utilization of mixingentropy effect for enhancing the formation of solid solutions ( $873 \mathrm{~K}$ at present work), the free energy of the high-entropy solid solution raised significantly relative to competing lowentropy phases. Thus, there is a tendency for $\mathrm{Zr}$ and $\mathrm{Hf}$ to be repelled from the solid solution matrix. Yet, this tendency is relatively weak, and no phase separations occurred for undoped
O-0. However, considering that the electronegativities of $\mathrm{Zr}$ (1.5) and $\mathrm{Hf}(1.4)$ are smaller than those of $\mathrm{Ti}$ (1.6) and $\mathrm{Nb}$ (1.7) (Gordy and Thomas, 1956), Zr and Hf are more attractive to Oxygen. This attraction effect would cause a strong tendency toward the $\mathrm{Zr}$-Hf repelling. Hence, after exposure at $873 \mathrm{~K}$ for $100 \mathrm{~h}$, the matrix of O-2.0 was decomposed into a $\mathrm{Zr}$-Hf-O-rich precipitate owing to the attraction between $\mathrm{Zr}-\mathrm{Hf}$ and Oxygen. As for the difference of element types comparing the OOCs with current precipitates, it might be attributed to the nonequilibrium rapid solidification during copper-mould casting. In the melt, the self-diffusion coefficient of atoms is usually inversely related to the atomic weight of elements, so $(\mathrm{O}, \mathrm{Ti}, \mathrm{Zr})$ atoms might aggregate and form OOCs. Also, it is possible that the equilibrium state of OOCs is enriched in $\mathrm{Ti}$ and $\mathrm{Zr}$, which needs further investigation in samples annealed at higher temperatures, such as SST alloys in the present work.
A

A SST

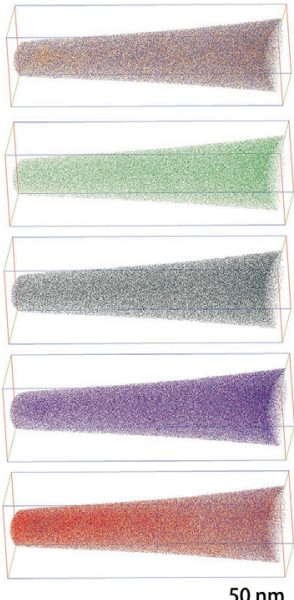

B

Hf

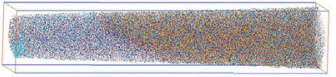

$\mathrm{Nb}$

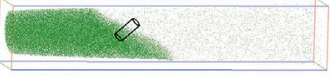

$\mathrm{Ti}$

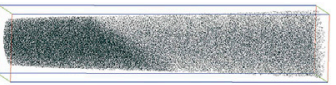

$\mathrm{Zr}$

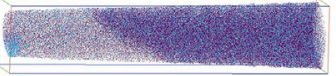

0

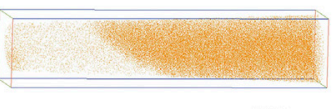

C

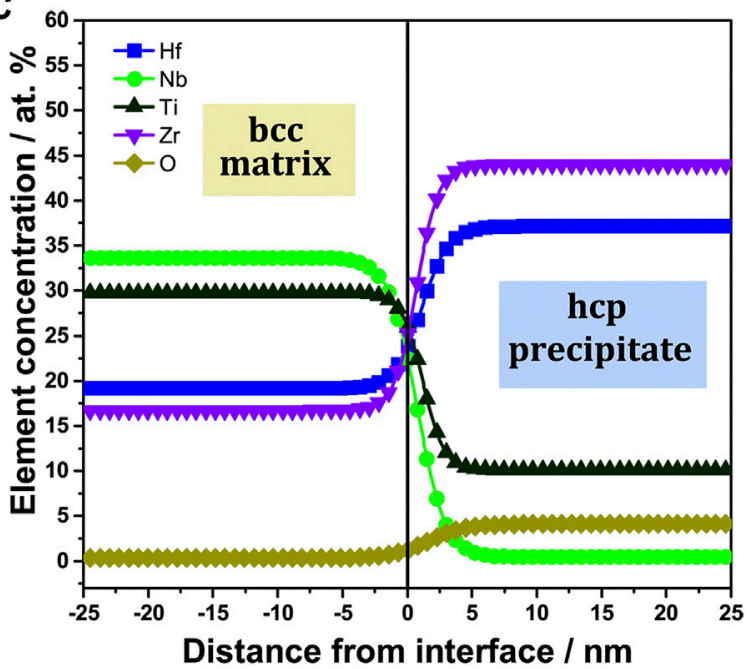

FIGURE 3 | 3D-reconstruction images for (A) O-2.0-SST and (B) O-2.0-STA, (C) Chemical composition along the long axis of the cylinder area marked in (B). 

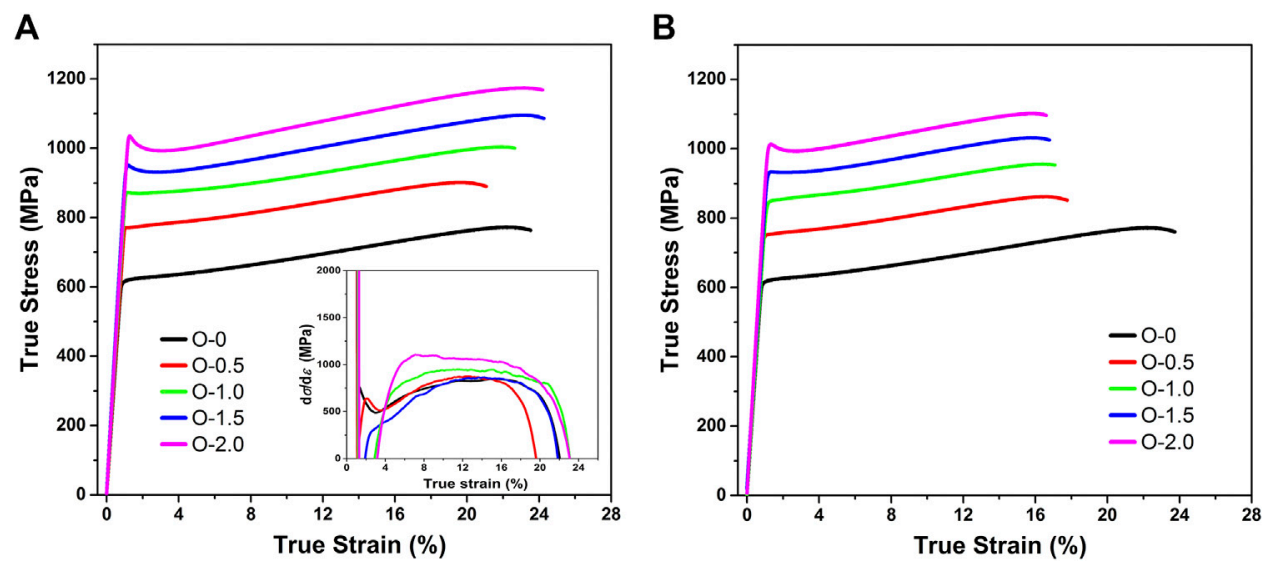

FIGURE 4 | Tensile true stress-strain cures of TiZrHfNbO refractory HEAs underwent (A) SST and (B) STA heat treatments.

\section{Tensile Properties}

Figure 4 shows tensile true stress-strain curves of the SST and STA alloys measured at room temperature. And it is illustrated that the yield strength (YS) increases significantly with increased Oxygen concentration both in SST and STA state. The YS of SST O-0 alloy is $\sim 610 \mathrm{MPa}$, while that of SST O-2.0 alloy is increased by $69 \%$, reaching up to $\sim 1,032 \mathrm{MPa}$. The SST alloys almost maintained the homogeneous uniform elongations at $\sim 24 \%$ as the Oxygen concentration increased to $2 \%$, although the addition of Oxygen firstly decreased the elongation slightly. Considering that OOCs play the critical roles in the toughening of the O-doped alloys, alloys with higher contents of Oxygen might
A

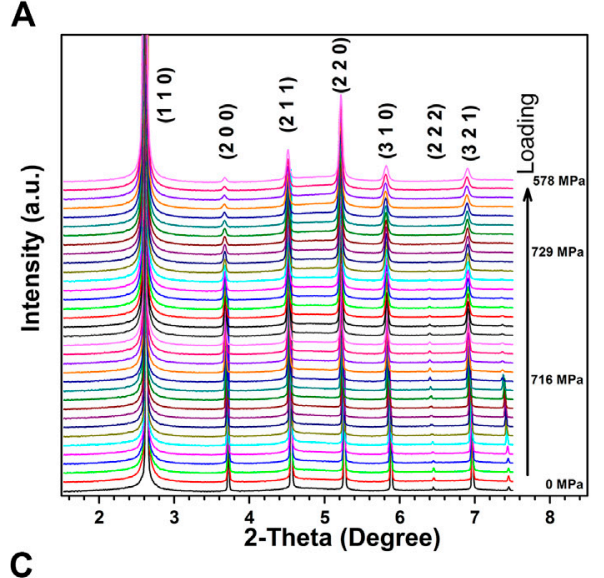

C

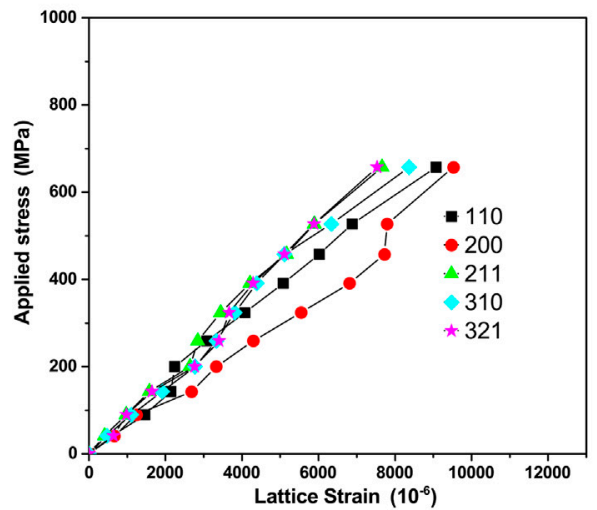

B
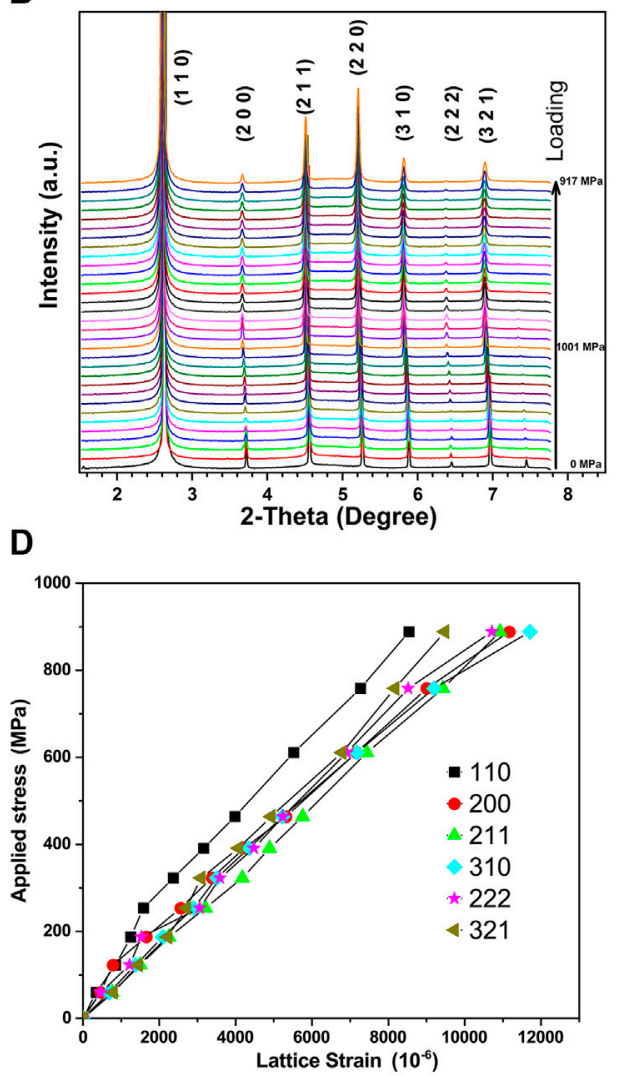

FIGURE 5 | The 1-D synchrotron X-ray diffraction profiles of the SST samples in the loading direction under different loadings, (A) O-0 and (B) O-1.5. Evolution of lattice strain of (C) O-O and (D) O-1.5 as a function of applied stress during tension. 
TABLE 1 | Single-crystal elastic constants, $\left(\mathrm{C}_{11}-\mathrm{C}_{12}\right)$ values and the anisotropy factor $\mathrm{A}=2 \mathrm{C}_{44} /\left(\mathrm{C}_{11}-\mathrm{C}_{12}\right)$ of SST O-0 and O-1.5 in comparison with those of $\mathrm{Nb}$ and "Gum Metal"

\begin{tabular}{lccccc}
\hline & $\mathbf{C}_{\mathbf{1 1}}$ & $\mathbf{C}_{\mathbf{1 2}}$ & $\mathbf{C}_{\mathbf{4 4}}$ & $\mathbf{C}_{\mathbf{1 1}}-\mathbf{C}_{\mathbf{1 2}}$ & $\mathbf{A}$ \\
\hline O-0 & 139.0 & 96.6 & 39.5 & 42.4 & 1.86 \\
O-1.5 & 151.9 & 115.1 & 44.6 & 36.8 & 2.43 \\
$\mathrm{Nb}$ & 246 & 134 & 28.7 & 112 & 0.51 \\
Gum metal & 125 & 93 & 28 & 32 & 1.75 \\
\hline
\end{tabular}

form more OOCs and hence result in higher toughening effects. This might explain the slight increase of elongations with increment of Oxygen concentration. As shown in inset of Figure 4A, the addition of Oxygen increases the work hardening rate during plastic deformation, especially for the alloys with higher Oxygen contents. The strength and elongation of the undoped STA O-0 alloy are very close to those of the SST O-0 alloy. This is not surprising since they have the same microstructure and no precipitates formed after STA process. It is noticeable that the elongations of the STA O-2.0 alloy dropped to $\sim 16 \%$, which is attributed to the precipitation of incoherent HCP phase along grain boundaries in these alloys. Moreover, the depletion of alloying elements in the BCC matrix caused by the precipitation also decreased the yield strengths of the STA alloys slightly. The above results show that after STA process, both strength and elongation were reduced in the O-doping alloys due to the transformation of OOCs into precipitates with HCP structure.

\section{IN Situ Characterization of Deformation Behavior}

To further investigate the effect of O-doping on the deformation behavior of HEAs, in situ synchrotron X-ray diffraction tensile experiments were conducted for SST O-0 and O-1.5 alloys. Figure 5 shows the evolution of diffraction patterns for SST O-0 and O-1.5 alloys during tensile deformation at room temperature. It can be clearly seen that no phase transformation occurred during the loading process for both alloys, indicating high structural stability for mechanical deformation. Figure 5C and 5D show the evolution of the lattice strains during elastic deformation for SST O-0 and O-1.5 alloys. It is illustrated that the lattice strain change is dependent on the grain orientations, indicating slight elastic anisotropy, which is common in BCC alloys. The $\{200\}$ grains of O-0 exhibit the largest elastic strain along the loading direction, and the other grains detected exhibit similar elastic strains. As for O-1.5, the $\{110\}$ grains exhibit the lowest elastic strain along the loading direction, and the other grains detected exhibit similar elastic strains. This trend indicates that addition of Oxygen alters the strength along specific crystal directions.

To further unveil the elastic deformation behavior of current alloys, the well-known Kroner's models for analyzing the diffraction elastic moduli are applied in the present work (Kröner, 1958; Gittus and Zarka, 1986; Wit, 1997; Gnäupel-Herold et al., 2010; Wu et al., 2014). By regressing the experimental data with Kroner's selfconsistent model, the single-crystal elastic constants of current HEAs were derived and listed in Table 1. As can be seen, addition of Oxygen increased all the single-crystal elastic constants and the shear anisotropy, $\mathrm{A}=2 \mathrm{C}_{44} /\left(\mathrm{C}_{11}-\mathrm{C}_{12}\right)$. To compare with other alloys with BCC structure, pure Niobium (Bolef, 1961) and the "Gum Metal" (Ti-36Nb-2Ta-3Zr-0.3O (wt\%))(Talling, 2008) was chosen. As shown in Table 1, the shear anisotropy value of $\mathrm{O}-0$ is close to the "Gum Metal," indicating that the elastic anisotropy behavior of current alloy is close to the corresponding BCC titanium alloy with similar constituent elements. Moreover, the $\left(\mathrm{C}_{11}-\mathrm{C}_{12}\right)$ values of current HEAs are larger than that of "Gum Metal." It is thought that higher $\left(\mathrm{C}_{11}-\mathrm{C}_{12}\right)$ value implies higher stability of BCC phase (Ikehata, 2004). And it can be proved by the fact that no phase transformation occurred in current HEAs, while stress-induced phase transformation was involved in "Gum Metal" (Talling, 2008).

\section{CONCLUSIONS}

In summary, phase stability of O-doping TiZrHfNbO HEAs were systematically investigated. Oxygen alloying in TiZrHfNb resulted in phase separation when annealed at $873 \mathrm{~K}$ for $100 \mathrm{~h}$. A HCP phase with lattice constants of $a \sim 0.3195 \mathrm{~nm}$ and $c \sim 0.5072 \mathrm{~nm}$ was precipitated from the BCC matrix. The orientation relationship between the HCP phase and the BCC matrix was revealed as $\left\{\begin{array}{lll}1 & \overline{1} & 1\end{array}\right\}_{\mathrm{HCP}} / /\left\{\begin{array}{lll}1 & \overline{1} & 0\end{array}\right\}_{\mathrm{BCC}}$ and $\left[\begin{array}{lll}0 & 1 & 1\end{array}\right]_{\mathrm{HCP}} / /\left[\begin{array}{lll}1 & 1 & 1\end{array}\right]_{\mathrm{BCC}}$. The HCP precipitates have been proved to be enriched with $\mathrm{Zr}$, Hf and $\mathrm{O}$ elements. For the TiZrHfNbO HEAs in SST state, addition of Oxygen significantly increased the yield strengths, and the plasticity were successfully maintained. However, the formation of the HCP precipitates in the STA state slightly reduced the yield strengths and deteriorated the plasticity. Structural evolution of SST O-0 and O-1.5 during tensile loading has been clarified. Single-crystal elastic constants of both alloys were evaluated, and were found to be similar to that of "Gum Metal" Ti alloy. The $\left(\mathrm{C}_{11}-\mathrm{C}_{12}\right)$ values of current HEAs are larger than that of "Gum Metal", indicating higher stability, and no phase transformation occurred in both current HEAs.

\section{DATA AVAILABILITY STATEMENT}

All datasets presented in this study are included in the article.

\section{AUTHOR CONTRIBUTIONS}

YW performed the experiments. YW and $\mathrm{XH}$ supervised the project. YW, QW, TW, DL and YW analyzed the data. YW wrote the paper. All authors commented on the manuscript.

\section{ACKNOWLEDGMENTS}

The authors would like to gratefully acknowledge the financial support from The National Key Research and Development Program of China (2016YFB0701402 and 2016YFB0300502), National Natural Science Foundation of China (Nos. 51531001 and 51771020), and Fundamental Research Funds for the Central Universities (FRF-TP-19-037A1). 


\section{REFERENCES}

Bolef, D. I. (1961). Elastic constants of single crystals of the bcc transition elements V, Nb, and Ta. J. Appl. Phys. 32(1), 100-105. doi:10.1063/1.1735933

Chen, S., Tong, Y., Tseng, K.-K., Yeh, J.-W., Poplawsky, J., Wen, J., et al. (2019). Phase transformations of HfNbTaTiZr high-entropy alloy at intermediate temperatures. Scripta Mater. 158, 50-56. doi:10.1016/j.scriptamat.2018.08.032

Gittus, J., and Zarka, J. (1986). "Statistical modeling" in modeling small deformations of polycrystals, edited by J. Gittus and J. Zarka (Elsevier Applied Science, London, New York, 1986), Chap. 8, pp. 229-291

Gnäupel-Herold, T., Brand, P. C., and Prask, H. J. (2010). Calculation of singlecrystal elastic constants for cubic crystal symmetry from powder diffraction data. J. Appl. Crystallogr. 31, 929-935. doi:10.1107/S002188989800898X

Gordy, W. and Oriville Thomas, W. J. (1956). Electronegativities of the elements. J. Chem. Phys. 24, 439-444. doi:10.1063/1.1742493

Ikehata, H., Nagasako, N., Furuta, T., Fukumoto, A., Miwa, K., and Saito, T. (2004). First-principles calculations for development of low elastic modulus Ti alloys. Phys. Rev. B 70, 174113. doi:10.1103/physrevb.70.174113

Kröner, E. (1958). Berechnung der elastischen Konstanten des Vielkristalls aus den Konstanten des Einkristalls. Ztschrift Für Physik 151, 504-518. doi:10.1007/ BF01337948

Lei, Z., Liu, X., Wu, Y., Wang, H., Jiang, S., Wang, S., et al. (2018). Enhanced strength and ductility in a high-entropy alloy via ordered oxygen complexes. Nature 563, 546-550. doi:10.1038/s41586-018-0685-y

Miller, M., Russell, K., and Thompson, G. Strategies for fabricating atom probe specimens with a dual beam FIB. (2005). Ultramicroscopy 102, 287-298. doi:10. 1016/j.ultramic.2004.10.011

Min, X., Bai, P., Emura, S., Ji, X., Cheng, C., Jiang, B., et al. (2016). Effect of oxygen content on deformation mode and corrosion behavior in $\beta$-type Ti-Mo alloy. Mater. Sci. Eng. 684,534-541. doi:10.1016/j.msea.2016.12.062

Pickering, E. J., Muñoz-Moreno, R., Stone, H. J., and Jones, N. G. (2016). Precipitation in the equiatomic high-entropy alloy CrMnFeCoNi. Scripta Mater. 113, 106-109. doi:10.1016/j.scriptamat.2015.10.025

Pogrebnjak, A., Yakushchenko, I., Bondar, O., Beresnev, V., Oyoshi, K., Amekura, H., et al. (2015). The microstructure of a multielement nanostructured (TiZrHfVNbTa) $\mathrm{N}$ coating and its resistance to irradiation with $\mathrm{Au}$-ions. Tech. Phys. Lett. 41, 1054-1057. doi:10.1134/s1063785015110085

Miracle, D., and Senkov, O. (2017). A critical review of high entropy alloys and related concepts. Acta Mater. 122, 448-511. doi:10.1016/j.actamat.2016.08. 081

Otto, F., Dlouhý, A., Pradeep, K. G., Kuběnová, M., Raabe, D., Eggeler, G., et al. (2016). Decomposition of the single-phase high-entropy alloy CrMnFeCoNi after prolonged anneals at intermediate temperatures. Acta Mater. 112, 40-52. doi:10.1016/j.actamat.2016.04.005

Schuh, B., Völker, B., Todt, J., Schell, N., Perrière, L., Li, J., et al. (2018). Thermodynamic instability of a nanocrystalline, single-phase TiZrNbHfTa alloy and its impact on the mechanical properties. Acta Mater. 142, 201-212. doi:10.1016/j.actamat.2017.09.035

Senkov, O., Pilchak, A., and Semiatin, S. (2018). Effect of cold deformation and annealing on the microstructure and tensile properties of a HfNbTaTiZr refractory high entropy alloy. Metall. Mater. Trans. 49, 2876-2892. doi:10. 1007/s11661-018-4646-8

Senkov, O., Scott, J., Senkova, S., Meisenkothen, F., Miracle, D., and Woodward, C. (2012). Microstructure and elevated temperature properties of a refractory TaNbHfZrTi alloy. J. Mater. Sci. 47, 4062-4074. doi:10.1007/s10853-012-6260-2
Senkov, O., and Semiatin, S. (2015). Microstructure and properties of a refractory high-entropy alloy after cold working. J. Alloys Compd. 649, 1110-1123. doi:10. 1016/j.jallcom.2015.07.209

Senkov, O., Senkova, S., Woodward, C., and Miracle, D. (2013). Low-density, refractory multi-principal element alloys of the $\mathrm{Cr}-\mathrm{Nb}-\mathrm{Ti}-\mathrm{V}-\mathrm{Zr}$ system: microstructure and phase analysis. Acta Mater. 61, 1545-1557. doi:10.1016/ j.actamat.2012.11.032

Stepanov, N., Yurchenko, N. Y., Zherebtsov, S., Tikhonovsky, M., and Salishchev, G. (2018). Aging behavior of the HfNbTaTiZr high entropy alloy. Mater. Lett. 211, 87-90. doi:10.1016/j.matlet.2017.09.094

Talling, R. J., Dashwood, R. J., Jackson, M., Kuramoto, S., and Dye, D. (2008). Determination of (C11-C12) in Ti-36Nb-2Ta-3Zr-0.3O (wt.\%) (Gum metal). Scripta Mater. 59, 669-672. doi:10.1016/j.scriptamat.2008.05.022

Takeuchi, A., and Inoue, A. (2005). Classification of bulk metallic glasses by atomic size difference heat of mixing and period of constituent elements and its application to characterization of the main alloying element. Mater. Trans. 46, 2817-2829. doi:10.2320/matertrans.46.2817

Wei, Q., Wang, L., Fu, Y., Qin, J., Lu, W., and Zhang, D. (2011). Influence of oxygen content on microstructure and mechanical properties of $\mathrm{Ti}-\mathrm{Nb}-\mathrm{Ta}-\mathrm{Zr}$ alloy. Mater. Des. 32, 2934-2939. doi:10.1016/j.matdes.2010.11.049

Vrtnik, S., Koželj, P., Meden, A., Maiti, S., Steurer, W., Feuerbacher, M., et al. (2017). Superconductivity in thermally annealed Ta-Nb-Hf-Zr-Ti high-entropy alloys. J. Alloys Compd. 695, 3530-3540. doi:10.1016/j.jallcom.2016.11.417

Wit, R. D. Diffraction elastic constants of a cubic polycrystal. (1997). J. Appl. Crystallogr. 30, 510-511. doi:10.1107/S0021889896014628

Wu, Y., Cai, Y., Wang, T., Si, J., Zhu, J., Wang, Y., et al. (2014). A refractory Hf25Nb25Ti25Zr25 high-entropy alloy with excellent structural stability and tensile properties. Mater. Lett. 130, 277-280. doi:10.1016/j.matlet.2014.05.134

Wu, Y., Liu, W. H., Wang, X. L., Ma, D., Stoica, A. D., Nieh, T. G., et al. (2014). Insitu neutron diffraction study of deformation behavior of a multi-component high-entropy alloy. Appl. Phys. Lett. 104, 633-693. doi:10.1063/1.4863748

Wu, Y., Si, J., Lin, D., Wang, T., Wang, W. Y., Wang, Y., et al. (2018). Phase stability and mechanical properties of AlHfNbTiZr high-entropy alloys. Mater. Sci. Eng. 724, 249-259. doi:10.1016/j.msea.2018.03.071

Wu, Z., Parish, C. M., and Bei, H. (2015). Nano-twin mediated plasticity in carboncontaining FeNiCoCrMn high entropy alloys. J. Alloys Compd. 647, 815-822. doi:10.1016/j.jallcom.2015.05.224

Yeh, J. W., Chen, S. K., Lin, S. J., Gan, J. Y., Chin, T. S., Shun, T. T., et al. (2004). Nanostructured high-entropy alloys with multiple principal elements: novel alloy design concepts and outcomes. Adv. Eng. Mater. 6, 299-303. doi:10.1002/ adem.200300567

Zhang, Y., Zuo, T. T., Tang, Z., Gao, M. C., Dahmen, K. A., Liaw, P. K., et al. (2014). Microstructures and properties of high-entropy alloys. Prog. Mater. Sci. 61 1-93. doi:10.1016/j.pmatsci.2013.10.001

Conflict of Interest: The authors declare that the research was conducted in the absence of any commercial or financial relationships that could be construed as a potential conflict of interest.

Copyright (C) $2020 \mathrm{Wu}$, Wang, Lin, Chen, Wang, Wang, Wang and Hui. This is an open-access article distributed under the terms of the Creative Commons Attribution License (CC BY). The use, distribution or reproduction in other forums is permitted, provided the original author(s) and the copyright owner(s) are credited and that the original publication in this journal is cited, in accordance with accepted academic practice. No use, distribution or reproduction is permitted which does not comply with these terms. 